\section{CASE OF RUPTURE OF THE HEART.}

Bт JOHN LOWE, M.B. \& C.M. Edin., ASSISTANT MEDICAL OFFICER, DURHAM COONTY ASYLOM, SEDGEFIELD.

MARY $\triangle$ NN A-, aged sixty-six, retired to rest in her usual health about eight o'clock on the evening of July $17 \mathrm{th}$. About four o'clock on the following morning the night attendant observed that she was sick and vomiting. She procured a cup of tea for the patient, who, after drinking it, seemed much better. About two hours later on she drank some more tea, and, at half-past eight walked down stairs unassisted, in charge of a nurse, and was placed in bed in another ward, where she could be more easily attended to. Those who had charge of her state that at this time she looked paler than usual and complained of feeling ill, but there was nothing about her appearance which led them to think that she was seriously ill, or that it was necessary to procure medical assistance. She was placed in bed to await the ordinary medical visit. About 10.30 A.M. an attendant observed that she breathed with difficulty and then suddenly became very pale. Thinking the prtient was dead, she went at once for the medical officer, who, on his arrival, almost immediately afterwards found that life was extinct. According to the attendant's account, she did not appear to suffer pain at any time during the attack.

Sectio cadaveris, twenty-four hours after death.-Weather warm. Body stout and well nourished. Cadaveric rigidity was present in the lower extremities, and hypostasis was well inarked. No marks of bruises or injuries of any kind. There was a large amount of subcutaneous fat, especially over the abdomen, where it was fully an inch in depth. The costal cartilages were partially ossified, rendering their section a matter of some difficulty. On opening the chest, the mediastinum was found to contain a large amount of adipose tissue, from which, near the base of the pericardium, blood was observed to be oozing freely. Careful removal of this fat brought into view the pericardium, which was much distended, and its cavity, on being opened, was found to contain a blood-clot (which completely enveloped the heart), along with a small quantity of fluid blood. A very small puncture of the pericardium existed near its base, evidently made by the point of the knife in cutting through the costal cartilage. The clot and fluid blood wejghed eight ounces. On removal of the clot the heart was found to be imbedded in masses of adipose tissue, and a rupture was seen in the left ventricular wall, situated immediately to the left of the sulcus ventriculorum, and running nearly parallel with it. 'This rupture measured about three-quarters of an inch in length, its lower extremity reaching to about an inch from the apex; its edges were ragged, and it was occluded by means of coagulated blood. The heart was then carefully removed for examination. Its substance was soft and flabby and pale in colour, and the walls of both ventricles were $a b-$ normally thin. The right ventricle was empty, but the left contained a blood-clot, part of which protruded through the rupture in its wall. The wall was thinner at the point of rupture than elsewhere, and was distinctly pouched in its immediate vicinity. The inner opening of the rupture was of less extent than the outer, being barely half an inch in length, and its edges were smooth. A partial rupture of the muscular fibres extended upwards and downwards from the upper and lower ends respectively of the internal opening. The valves were healthy and competent. Patches of atheroma existed in the wall of the aorta, a little above its origin.-Both lungs were adherent by fibrous bands at the apices, the left more especially so, and both were emphy. sematous and somewhat congested throughout - Abromen : Liver fatty; spleen soft and pulpy; kidneys and uterus of normal appearance.-Head: The inner table of the skull was abnormally thick and brittle. Extensive adhesions of the dura mater existed in and near the mesian line. 'I'be sinuses were gnrged, and there was considerable atrophy of the frontal convilutions.

Remarks - This case, compared with that reported in THE LANCET of July $13 \mathrm{th}$, presents some resemblauces as well as points of difference. It resembles the case referred to in tbat sickness was the first symptom of anything being amiss, and in that the attack came on when the patient was lying quietly in bed, after having retired the previous evening in ber usual bealth. The chief points of difference are:1. That the patient in this case belonged to the female sex, n which rupture of the heart occurs more rarely than in the male. 2. That she recovered to some extent from the attack of sickness, and was able to walk downstairs some hours afterwards without assistance. 3. That she did not appear to suffer pain in the chest or elservere previous to death. 4. That the rupture existed in the wall of the left ventricle in place of the right.

I am inclined to think that in this case a very small opening had at first taken place in the ventricular wall, from which a gradual oozing of blood ensned, causing the sickness from which the patient at first suffered. A com. plete and extensive rupture then occurring suddenly, instantaneous death was the result. It is certainly difficult to explain how the patient improved for a time; but this seems to me the most reasonable interpretation of the symptoms. The small puncture in the pericardium accounted for the onzing of blood from the adipose tissue in the mediastinum observed at the post-mortem examination. Durham County Asylum.

\section{A CASE OF \\ BONY TUMOUR IN THE SUBSTANCE OF THE BRAIN.}

BY WYKEHAM H. LYDALL, M.R.C.S. ENG.

E. F-, aged fifty-six, widow, had suffered from epileptic fits for five years, and occasionally complained of pain over the brow. In general she seemed cheerful and in good health, with the exception of occasional lassitude, resulting, in a great measure, from the violence of the fits.

On September 9th she was taken in a severe fit at 8 A.M., which continued without the least intermission till 4 P.M., when she died.

Autopsy, twenty hours after death.-The body was well nourisbed; no rigor mortis. On removing the calvaria a quantity of fluid escaped external to the dura mater, which was much thickened. The brain was slightly congested, the ventricles containing about a couple of drachms of fluid. Over the right brow the substance of the brain presented a pinkish hue, and had thoroughly softened down to the size of a ben's egg. On caretul examination this sof tened mass was found to contain a quantity of gritty matter, which, on cleansing, proved to be bone. One piece measured a little more than half an inch in length, and a quantity had become matted together to the size of a large bazel-nut. The lungs were bealthy; the heart thin, fatty, and friable. There was no appearance of calcareous deposit, the valves being bealthy. 'The kidneys were large; the left had an abscess on the surface, and contained hydatids. The liver, spleen, and stomach appeared healtby. Death doubtless occurred from effusion on the brain and syncope.

There is no history of a blow or fall of any kind to account for the disease in the brain; and the bone being found embedded in the substance of the brain precludes the idea of any growth from the calvaria. The arteries being found elastic and healthy, it could scarcely have formed from calcareous degeneration. With regard to this being the result of an abscess there is no history to bear it out.

The case is one of interest, as showing what may, in a measure, be the cause of epilepsy, and so give additional light on a so-called greatly increasing disease.

Necklenburgh-square, W.C.

Chloride of Potassium in EPIlepsy. - Dr. Lander advocates this salt as better than bromide of potassium in epilepsy. He finds it is more active, costs fivesixths less, and has not the inconvenience of the secondary effects of bromide of potassium. He begins with small doses, and has continued the use of the drug for several months without any bad conseqnences in daily doses of from 3 grammes 50, to 5 grammes 50 ( 1 to 2 drachms). Moreover, Dr. Lander thinks that the bromide is converted into a chloride in the stomach, so be suggests the immediate use of the chloride.-Echo Méd. et Pharm. Belge. 